\title{
Liquid Phase Adsorption of Rhodamine B Dye onto Acid-treated Raphia hookeri Fruit Epicarp: Isotherms, Kinetics and Thermodynamics Studies
}

\author{
Adejumoke Abosede Inyinbor ${ }^{a, *}$, Folahan Amoo Adekola ${ }^{b}$ and Gabriel Ademola Olatunji \\ ${ }^{a}$ Department of Physical Sciences, Landmark University, P.M.B 1001, Omu Aran, Nigeria. \\ ${ }^{b}$ Department of Industrial Chemistry, University of Ilorin, P.M.B 1515, Ilorin, Nigeria.
}

Received 30 May 2016, revised 9 August 2016, accepted 12 August 2016.

\begin{abstract}
Novel adsorbent was prepared from the waste of Raphia hookeri fruit via acid treatments (ARH). The Brunauer-Emmett-Teller (BET) surface area of ARH was obtained to be $1.86 \mathrm{~m}^{2} \mathrm{~g}^{-1}$. Large surface pores evidently exposed by the scanning electron microscopic studies characterized ARH. Active surface functional groups were also revealed by the infrared spectroscopic studies. These characteristics resulted in ARH effectiveness in Rhodamine B (RhB) dye removal, with $98.46 \%$ dye removal from $50 \mathrm{mg} \mathrm{L}^{-1} \mathrm{RhB}$ solution. Maximum adsorption was obtained at $\mathrm{pH}$ of 3 . Equilibrium adsorption data fitted best into the Langmuir adsorption isotherm, with maximum monolayer adsorption capacity of $166.67 \mathrm{mg} \mathrm{g}^{-1}$. Pseudo-second-order kinetics best describe the RhB-ARH adsorption kinetic data. Energy of adsorption obtained from the D-R model was greater than $8 \mathrm{~kJ} \mathrm{~mol}^{-1}$, suggesting that the uptake of $\mathrm{RhB}$ onto $\mathrm{ARH}$ was chemical in nature. Desorption efficiency followed the order $\mathrm{CH}_{3} \mathrm{COOH}>\mathrm{HCl}>\mathrm{H}_{2} \mathrm{O}$ with highest desorption percentage of $36.36 \%$.
\end{abstract}

KEYWORDS

Raphia hookeri, biomass, rhodamine B, kinetics.

\section{Introduction}

Water pollution has become a global challenge. The desire for wealth creation continues to spur up various industries; thereby resulting into release of various toxicants into the environment. ${ }^{1}$ Discharges from dye-consuming industries contain loads of dye molecules identified at first by their colours. Dye molecules persist in the environment, their colours impede light penetrations into the water body, and reduces dissolved oxygen, thus threatens aquatic ecosystems and organism; as well as poses serious health challenges to human. ${ }^{2}$ For instance, RhB, a xanthenes dye widely used in various dye-utilizing industries is known to cause respiratory, eye and skin irritations, as well as gastrointestinal disorders. ${ }^{3}$ Effective treatment of effluents laden with $\mathrm{RhB}$ or other dyes, should be implemented before their discharge into the environment.

Industries within the developing economy avoid conventional methods of effluents treatments due to their economic implications, limitations, and complexities. The easy operational techniques as well as ability to remove very low concentrations of pollutants gave adsorption using activated carbon an advantage over other conventional methods of effluents treatment. ${ }^{4}$ The use of activated carbons in effluent treatment dates back to ancient Indian and Egyptian days. Raphael von Ostrejko, however, developed and patented the commercial activated carbon currently in use during the late 19th/early 20th century. ${ }^{5}$ Activated carbon has been greatly used in the treatment of effluents with loads of organic compounds. ${ }^{6}$ However, since the high cost of activated carbon is as a result of the precursors in use for their preparation, environmentalists therefore seek other precursors as well as alternative sorbent. ${ }^{7,8}$ Various low-cost bioadsorbents

To whom correspondence should be addressed.

E-mail: inyinbor.adejumoke@ @landmarkuniversity.edu.ng such as clay, industrial wastes, and agricultural wastes have textural, structural, and compositional potentials to serve as alternatives to activated carbon.

Agricultural wastes, as well as other waste materials such as coconut husk, ${ }^{7}$ rice husk, ${ }^{9}$ tamarind wood, ${ }^{10}$ Peach stone, ${ }^{11}$ cocoa pod husk, ${ }_{12}^{12}$ Bamboo, ${ }_{13}^{13}$ Periwinkle shell, ${ }^{14}$ sugar cane bagasse, ${ }^{15}$ Apricot stone, ${ }^{16}$ peanut shell,,$^{17}$ corncob, ${ }^{18}$ apple wastes, ${ }^{19}$ wood saw dust, ${ }^{20}$ Bengal gram husk, ${ }_{,}^{21}$ Moroccan clay, ${ }^{22}$ Peat and coconut fibres, ${ }^{23}$ Lentibulariaceae ${ }^{24}$ waste pea shell, ${ }^{25}$ chir pine saw dust, ${ }^{26}$ as well as Raphia hookeri fruit epicarp, ${ }^{27}$ ' have been utilized as cheap alternatives for activated carbon preparations and biosorbents for various pollutants uptake.

Several advantages accompany the use of biosorbents in the treatment of wastewater. They include environmental protection and waste management. Materials that would have ordinarily been disposed off, have become useful environmental remediation tools. Another advantage is the availability of abundant and inexhaustible/renewable material sources. Most importantly, the surface of a biosorbent can be tailored towards the uptake of a specific pollutant or a group of pollutants, via surface modification or functionalization. Surface modification and/or functionalization, affects the surface chemistry of a biosorbent and may also improve adsorption potential. Acid treatment for instance, is known to increase adsorbent porosity vis-à-vis its surface area. ${ }^{28}$ Consequently, increase in the porosity of adsorbent will increase its adsorption potential.

In our previous work, ${ }^{29}$ we employed a new approach of biomaterial fibre impregnation using concentrated acid and subsequent thermal treatment in order to blow the fibre open, thus leaving large pores on the biomaterial surface. Such large pores could act as medium for transporting large molecules into the adsorbent. Dika nut waste was utilized as biomaterials. This 
work, however, utilized a novel biomass (Raphia hookeri fruit epicarp), which belongs to the Palmaceae family. Waste from this family is usually characterized by high fixed carbon content, thus making them good precursor for activated carbon preparation. To the best of our knowledge, the application of this biomass in environmental remediation has not been earlier reported. We recently reported the use of raw $\mathrm{RH}$ in $\mathrm{RhB}$ uptake. ${ }^{27}$ However, in a bid to enhance sorption capacity, in this study, $\mathrm{RH}$ was modified via acid treatment. Considering the wide usage of $\mathrm{RhB}$, its toxicity as well as the great desires for a clean and sustainable environment, such studies as this is of great importance. The present study therefore reports the uptake of Rhodamine B (RhB) dye from aqueous solution, onto the prepared novel adsorbent, with focus on various adsorption operational parameters. Detailed kinetics, isothermal, as well as thermodynamics studies of the adsorption system; are reported. Adsorption mechanism and desorption studies were employed to justify the mode of $\mathrm{RhB}$ uptake onto the prepared adsorbent. Statistical tools were also employed to establish the best kinetic, as well as isotherm model for the adsorption studies.

\section{Materials and Methods}

\subsection{Materials}

Analytical grade reagents were used, hence no purification was carried out on them. Sigma Aldrich supplied concentrated $\mathrm{H}_{2} \mathrm{SO}_{4}$ while $\mathrm{BDH}$ supplied $\mathrm{RhB}$. The chemical structure of Rhodamine B is presented in Fig. 1, while the characteristics of $\mathrm{RhB}$ are listed in Table 1. Raphia hookeri (RH) epicarp were collected from local farmers in Makogi, Edu local government, Kwara State. Nigeria.

\subsection{Adsorbate Preparation}

A $1000 \mathrm{mg} \mathrm{L}^{-1}$ stock solution of RhB was prepared by dissolving accurately weighed mass of $\mathrm{RhB}$ in $1 \mathrm{dm}^{3}$ deionized water. Other working solutions that are of lower concentrations were subsequently prepared from the parent solution.

\subsection{Biomass Pretreatment and Adsorbent Preparation}

RH was thoroughly washed and dried in an oven, operated at<smiles></smiles>

Figure 1 Chemical structure of Rhodamine B dye.

Table 1 Properties of Rhodamine B.

\begin{tabular}{ll}
\hline Parameters & Values \\
\hline Suggested name & Rhodamine B \\
C.I number & 45170 \\
C.I name & Basic Violet 10 \\
Class & Rhodamine \\
$\lambda_{\max }$ & $554 \mathrm{~nm}$ \\
Molecular formula & $\mathrm{C}_{28} \mathrm{H}_{31} \mathrm{~N}_{2} \mathrm{O}_{3} \mathrm{Cl}$ \\
Molecular weight & 479.02 \\
\hline
\end{tabular}

low temperature over night. Subsequently washed, dried biomass was pulverized and screened into a particle size of 150-250 $\mu \mathrm{m}$. Raphia hookeri (RH) fruit epicarp was treated using concentrated sulphuric acid as described in our earlier reported work. ${ }^{29}$ ARH was subsequently stored in airtight containers for further characterization and applications.

\subsection{Adsorbent Characterization}

The characteristics of adsorbent surface is quite important in adsorption studies, hence the surface chemistry, surface area and surface morphology, were investigated.

\subsubsection{Surface Chemistry Determination}

A Bruker Alpha FTIR spectrometer was used for functional group analysis. Discs preparation was done using an agate morta. The adsorbent (ARH) and $\mathrm{KBr}$ (Merck, for spectroscopy) were mixed in a ratio 1 to 500 , and the mixture was subsequently pressed at 10 tonnes $\mathrm{cm}^{-2}$ for $15 \mathrm{~min}$ under vacuum. The $\mathrm{pH}$ point of zero charge determination ( $\mathrm{pHpzc}$ ) gives insight into the adsorbent surface charge in different solution media. This was done by transferring $50 \mathrm{~cm}^{3} \mathrm{NaCl}$ solution into series of nine conical flasks. The $\mathrm{pH}$ of the solutions was adjusted with $\mathrm{NaOH}$ or $\mathrm{HCl}$ between $\mathrm{pH} 2$ and 10 . A $0.1 \mathrm{~g}$ of the adsorbent was added to each of the flask; and the containers were sealed and placed on a shaker for $24 \mathrm{~h}$ after which the final $\mathrm{pH}$ was measured. The difference between the initial and final $\mathrm{pH}$ were calculated and plotted against the $\mathrm{pH}$ initial. The point of intersection of the resulting curve with vertical axis gave the $\mathrm{pHpzc}$.

\subsubsection{Surface Area and Porosity Analysis}

BET surface area and average pore diameter were determined using a Micrometrics Tristar II surface area and porosity analyzer. Samples were degassed under vacuum at $90^{\circ} \mathrm{C}$ for $1 \mathrm{~h}$ and the temperature was further ramped up to $200^{\circ} \mathrm{C}$ overnight.

\subsubsection{Surface Morphology and Elemental Composition}

The surface morphology and elemental analysis were done using FEIESEM Quanta 200 for SEM and EDX.

\subsection{Batch Adsorption Studies}

\subsubsection{Effects of Adsorbate $\mathrm{pH}$}

A $0.1 \mathrm{~g}$ of ARH was added to $100 \mathrm{~cm}^{3}$ of $100 \mathrm{mg} \mathrm{L}^{-1} \mathrm{RhB}$ solution whose initial $\mathrm{pH}$ had been varied between 2 and 10 using $0.1 \mathrm{M}$ $\mathrm{HCl}$ or $0.1 \mathrm{M} \mathrm{NaOH}$. The mixture was agitated for $4 \mathrm{~h}$ on a thermostated water bath shaker, operated at a temperature of $26{ }^{\circ} \mathrm{C}$ and speed of $130 \mathrm{rpm}$. The supernatant was separated using a centrifuge and the concentration of unadsorbed dye was determined using a Beckman Coulter Du 730UV-visible spectrophotometer operated at $554 \mathrm{~nm}$. Percentage removal was calculated according to Equation 1. The optimum $\mathrm{pH}$ obtained was used in subsequent adsorption studies.

$$
\% \text { Removal }=\frac{\left(C_{i}-C_{f}\right)}{C_{i}} \times 100
$$

where $C_{i}$ and $C_{f}$ are concentrations of $\mathrm{RhB}$ in solution at initial and at given time $t$, respectively.

\subsubsection{Effects of Initial Adsorbate Concentration/Contact Time}

Varying RhB concentration ( $50 \mathrm{mg} \mathrm{L}^{-1}$ to $400 \mathrm{mg} \mathrm{L}^{-1}$ ) was utilized for this study. $0.1 \mathrm{~g}$ of ARH was agitated with $100 \mathrm{~cm}^{3}$ of $\mathrm{RhB}$ solution of each concentration in different $250 \mathrm{~cm}^{3}$ flasks. Samples were withdrawn at different time intervals, centrifuged and the supernatant was analyzed for change in dye concentration 
using a UV-visible spectrophotometer. This process continued until equilibrium was attained. The quantity of RhB adsorbed at a given time $q_{t}\left(\mathrm{mg} \mathrm{g}^{-1}\right)$ was calculated using:

$$
q_{t}=\frac{\left(C_{i}-C_{t}\right) X V}{M}
$$

where $C_{i}$ and $C_{t}$ are concentrations of RhB in solution at initial and at time $t, V$ is the volume in litre and $M$ is the mass of the adsorbent in $\mathrm{g}$.

\subsubsection{Effects of Adsorbent Dosage}

A given dose of the adsorbent (between $1 \mathrm{~g} \mathrm{~L}^{-1}$ and $5 \mathrm{~g} \mathrm{~L}^{-1}$ ) was agitated with $100 \mathrm{~cm}^{3}$ solution of $\mathrm{RhB}$ at a given time. Other conditions such as agitation speed, temperature, and initial concentration were maintained at $130 \mathrm{rpm}, 26^{\circ} \mathrm{C}$ and $100 \mathrm{mg} \mathrm{L}^{-1}$, respectively. Unadsorbed dye was determined as earlier described and percentage dye removal was calculated.

\subsubsection{Effects of Temperature}

Adsorptions of RhB onto the prepared adsorbents were investigated as a function of temperature, $100 \mathrm{~cm}^{3}$ initial dye concentration of $100 \mathrm{mg} \mathrm{L}^{-1}$ was added to $1 \mathrm{~g} \mathrm{~L}^{-1}$ of each adsorbent in separate $250 \mathrm{~cm}^{3}$ glass conical flask. The mixture was then agitated at $130 \mathrm{rpm}$ for a predetermined time while varying the temperature between 303 and $333 \mathrm{~K}$. Unadsorbed dye was determined as earlier described and percentage dye removal was calculated.

\subsection{Mathematical Modelling}

Isotherms and kinetics models give insight into adsorption types and mechanism. Four isotherms and five kinetics models was employed to analyze the adsorption data in this study. Feasibility and spontaneity of the adsorption process was ascertained via thermodynamic studies.

\subsubsection{Isotherms Models}

Langmuir isotherm ${ }^{30}$ assumes that adsorbate molecules bind to a uniform surface. Langmuir equation is expressed in Equation 3. $C_{\mathrm{e}}$ and $q_{\mathrm{e}}$ are concentration of adsorbate in solution at equilibrium measured in $\mathrm{mg} \mathrm{L}^{-1}$ and quantity of dye adsorbed at equilibrium in $\mathrm{mg} \mathrm{g}^{-1}$, respectively. $q_{\max }$ is the maximum monolayer adsorption capacity of adsorbent $\left(\mathrm{mg} \mathrm{g}^{-1}\right)$ and $K_{\mathrm{L}}$ is the Langmuir adsorption constant $\left(\mathrm{L} \mathrm{mg}^{-1}\right)$. The dimensionless $R_{\mathrm{L}}$, which explains the favourability of the adsorption process can be obtained from Equation 3a.

$$
\begin{aligned}
& \frac{C_{\mathrm{e}}}{q_{\mathrm{e}}}=\frac{C_{\mathrm{e}}}{q_{\max }}+\frac{1}{q_{\max } K_{\mathrm{L}}} \\
& R_{\mathrm{L}}=\frac{1}{\left(1+K_{\mathrm{L}} C_{\mathrm{O}}\right)}
\end{aligned}
$$

Freundlich isotherm ${ }^{31}$ describes a multilayer adsorption Mathematical Equation 4 expresses this isotherm model. $C_{\mathrm{e}}$ and $q_{\mathrm{e}}$ are concentration of adsorbate in solution at equilibrium measured in $\mathrm{mg} \mathrm{L}^{-1}$ and quantity of dye adsorbed at equilibrium in $\mathrm{mg} \mathrm{g}^{-1}$, respectively. $K_{\mathrm{f}}$ and $n$ are Freundlich constants incorporating the factors affecting the adsorption capacity and adsorption intensity, respectively.

$$
\log q_{\mathrm{e}}=\frac{1}{n} \log C_{\mathrm{e}}+\log K_{\mathrm{f}}
$$

Temkin isotherm, ${ }^{32}$ which assumes linear rather than logarithmic decrease of heat of adsorption while ignoring extremely low and very high concentration. Temkin equation is expressed by Equation 5. $A\left(\mathrm{~L} \mathrm{~g}^{-1}\right)$ and B are Temkin isotherm constants, $b$ $\left(\mathrm{J} \mathrm{mol}^{-1}\right)$ is a constant related to the heat of absorption and can be determined using Equation $5 \mathrm{a}$. Where $T$ is the absolute temperature $(\mathrm{K})$ and $R$ is the gas constant $\left(\mathrm{J} \mathrm{mol}^{-1} \mathrm{~K}\right)$.

$$
\begin{aligned}
& q_{\mathrm{e}}=\mathrm{B} \ln A+B \ln C_{\mathrm{e}} \\
& B=R T / b
\end{aligned}
$$

Dubinin Radushkevich (D-R) model ${ }^{33}$ gives insight into the biomass porosity as well as the adsorption energy. D-R model is expressed by Equation 6, Polanyi potential $(\varepsilon)$ and the mean energy of adsorption $(E)$ can be obtained by Equations $6 a$ and $6 \mathrm{~b}$, respectively. The value of adsorption energy $(E)$ obtained from the $\mathrm{D}-\mathrm{R}$ model further provides information as to whether adsorption process is physical or chemical in nature, $\beta$ which is the activity coefficient helps in obtaining the mean sorption energy $E\left(\mathrm{~kJ} \mathrm{~mol}^{-1}\right)$.

$$
\begin{aligned}
& \ln q_{\mathrm{e}}=\ln q_{\mathrm{o}}-\beta^{2} \\
& =R T \ln \left(1+\frac{1}{C_{\mathrm{e}}}\right) \\
& E=\sqrt{\frac{1}{2 \beta}}
\end{aligned}
$$

\subsubsection{Kinetics Model}

In order to understand the adsorption process better, the pseudo-first-order kinetics model of Lagergren, ${ }^{34}$ pseudosecond-order, ${ }^{35}$ Elovich, ${ }^{36}$ and Avrami ${ }^{37}$ kinetics models were used to test the kinetics data while the intraparticle diffusion of Weber and Morris ${ }^{38}$ investigated the mechanism of adsorption.

The pseudo-first-order kinetics model is expressed mathematically by Equation $7, q_{\mathrm{e}}$ and $q_{t}$ are quantity of $\mathrm{RhB}$ adsorbed at equilibrium, and at time $t\left(\mathrm{mg} \mathrm{g}^{-1}\right)$, respectively, $k_{1}$ is the pseudofirst-order rate constant $\left(\mathrm{min}^{-1}\right)$;

$$
\ln \left(q_{\mathrm{e}}-q_{t}\right)=\ln q_{\mathrm{e}}-k_{1} t
$$

Pseudo-second-order kinetic model expressed by Equation 8 , $q_{\mathrm{e}}$ and $q_{t}$ are quantity of $\mathrm{RhB}$ adsorbed at equilibrium, and at time $t\left(\mathrm{mg} \mathrm{g}^{-1}\right)$, respectively, while $k_{2}$ is the pseudo-first-order rate constant $\left(\mathrm{g} \mathrm{mg}^{-1} \mathrm{~min}^{-1}\right)$;

$$
\frac{t}{q_{t}}=\frac{1}{k_{2} q_{\mathrm{e}}^{2}}+\frac{t}{q_{\mathrm{e}}}
$$

Elovich kinetic model is expressed by Equation 9, the Elovich constants $\alpha$ and $\beta$ may explain the chemisorption rate and extent of surface coverage, respectively.

$$
q_{t}=\frac{1}{\beta} \ln (\alpha \beta)+\frac{1}{\beta} \ln t
$$

Avrami kinetic model is expressed by Equation $10, K_{\mathrm{AV}}$ and $n_{\mathrm{AV}}$ which can be obtained from the intercept and slope of the plot of $\ln [-\ln (1-\alpha)]$ against $\ln t$ are the Avrami constant and the Avrami model exponent of time related to the change in mechanism of adsorption.

$$
\ln [-\ln (1-\alpha)]=n_{\mathrm{AV}} K_{\mathrm{AV}}+n_{\mathrm{AV}} \ln t
$$

The intraparticle diffusion model by Weber and Morris is expressed by Equation 11, adsorption mechanism is well explained by the plot of quantity adsorbed at time $t\left(q_{t}\right)$ against the square root of time $(t)$. A single linear adsorption profile or a multilayer adsorption profile may result from the plot of $q_{t}$ against $t^{1 / 2}$ and $C$ is the boundary layer thickness.

$$
q_{\mathrm{t}}=k_{\mathrm{diff}} t^{1 / 2}+C
$$

\subsubsection{Validation of Adsorption Kinetics}

Kinetics and isothermal models were validated using Sum square of error (SSE), chi-square $\left(\chi^{2}\right)$ and the normalized standard deviation $\left(\Delta q_{\mathrm{e}} \%\right)$, represented by Equations 12, 13 and 14; 


$$
\begin{aligned}
& \mathrm{SSE}=\sum_{i=1}^{n}\left(q_{\mathrm{cal}}-q_{\mathrm{exp}}\right) \\
& \chi^{2}=\sum_{i=1}^{n} \frac{\left(q_{\mathrm{exp}}-q_{\mathrm{cal}}\right)^{2}}{q_{\mathrm{cal}}} \\
& \Delta q_{\mathrm{e}}(\%)=100 \sqrt{\left[\frac{\left(q_{\mathrm{exp}}-q_{\mathrm{cal}}\right) / q_{\exp }}{N-1}\right]}
\end{aligned}
$$

\subsubsection{Thermodynamic Studies}

Thermodynamic parameters that explain feasibility, spontaneity and the nature of adsorbate-adsorbent interactions $\left(\Delta G^{\circ}\right.$, $\Delta H^{\circ}$ and $\Delta S^{\circ}$ ) were calculated using the mathematical relations 15 and 16;

$$
\begin{aligned}
& \ln K_{0} \frac{\Delta S^{\circ}}{R}-\frac{\Delta H^{\circ}}{R T} \\
& \Delta G^{\circ}=R T \ln K_{\mathrm{o}}
\end{aligned}
$$

where $T$ is the temperature in Kelvin, $R$ is the gas constant and $K_{0}$ can be obtained from equilibrium concentration and quantity adsorbed at equilibrium. The values of enthalpy $\left(\Delta H^{\circ}\right)$ and $\Delta S^{\circ}$ can be obtained from the plot of $\ln K_{\mathrm{o}}$ versus $1 / T$.

\subsection{Spent Adsorbent Regeneration Studies}

Adsorbents regeneration is very important in adsorption study, thus leaching/desorption of RhB from adsorbent surface was investigated using three eluents (water, $0.1 \mathrm{M} \mathrm{HCl}$ and $0.1 \mathrm{M}$ $\mathrm{CH}_{3} \mathrm{COOH}$ ). A fixed mass of fresh adsorbent was loaded with $\mathrm{RhB}$ by agitation it with a fixed volume and a fixed concentration of RhB at its optimum $\mathrm{pH}$ for $120 \mathrm{~min}$. The loaded adsorbent was separated by centrifugation and the residual $\mathrm{RhB}$ concentration determined spectrophotometrically. RhB loaded adsorbent was subsequently washed with water gently to remove unadsorbed dye. Dry loaded adsorbent was contacted with $100 \mathrm{~cm}^{3}$ of each desorbing eluent and was shaken for a predetermined time. The desorbed RhB was determined spectrophotometrically and the desorption efficiency was calculated using the mathematical relation 17;

$$
\text { Desorption efficiency }(\%)=\frac{q_{\mathrm{de}}}{q_{\mathrm{ad}}} \times 100
$$

Where $q_{\mathrm{de}}$ is the quantity desorbed by each of the eluent and $q_{\mathrm{ad}}$ is the adsorbed quantity during loading.

\section{Results and Discussion}

\subsection{Characteristics of ARH}

Low ash content characterized ARH (Table 2), this suggests that ARH is easily degradable. The $\mathrm{pH}$ and the $\mathrm{pHpzc}$ are near neutral suggesting that percentage RhB adsorption is expected

Table 2 Characteristics of ARH.

\begin{tabular}{lr}
\hline Parameters & Values \\
\cline { 2 - 2 } & ARH \\
\hline $\mathrm{pH}$ & 6.43 \\
$\mathrm{pHpzc}$ & 6.80 \\
Bulk density & 1.25 \\
Moisture content $/ \%$ & 7.90 \\
Ash content $/ \%$ & 0.20 \\
BET surface area $/ \mathrm{m}^{2} \mathrm{~g}^{-1}$ & 1.86 \\
Elemental composition $/ \%$ & \\
Carbon & 74.49 \\
Oxygen & 22.99 \\
Potassium & 1.34 \\
\hline
\end{tabular}

to increase as adsorbate solution $\mathrm{pH}$ increases. The BET surface area of ARH is low $\left(1.86 \mathrm{~m}^{2} \mathrm{~g}^{-1}\right)$, low surface area is a characteristic of agro waste. ${ }^{39}$ Agro waste framework is lined with various functional groups thus resulting into low porosity. ${ }^{40,41}$ Low affinity for water, high carbon content and bulk density all presents ARH a suitable adsorbent for dye uptake. ${ }^{39}$

Figure 2a,b shows the FTIR spectral of RH and ARH before RhB uptake and FTIR spectrum of ARH after RhB uptake, respectively. Vivid absorption bands occurs at $1108 \mathrm{~cm}^{-1}$, $1293 \mathrm{~cm}^{-1}, 1384 \mathrm{~cm}^{-1}, 1595 \mathrm{~cm}^{-1}$ and $3288 \mathrm{~cm}^{-1}$, this corresponds to $\mathrm{C}-\mathrm{OH}$ or $\mathrm{C}-\mathrm{N}$ stretching vibrations, $\mathrm{C}-\mathrm{O}-\mathrm{C}$ vibrations of lignin, $\mathrm{C}-\mathrm{C}$ vibrations of aromatics, $\mathrm{C}=\mathrm{C}$ vibrations of aromatic and $\mathrm{O}-\mathrm{H}$ or $\mathrm{N}-\mathrm{H}$ stretching vibrations, respectively. In $\mathrm{RH}$ observed peak at $2843 \mathrm{~cm}^{-1}$ corresponds to $-\mathrm{C}-\mathrm{H}$ vibration of methylene. Elimination of volatile compounds and breakdown of hemicellulose resulted into the disappearance of methylene vibration band after acid treatment. After RhB adsorption, shift in various absorption bands occurred suggesting that there corresponding functional group may have participated in $\mathrm{RhB}$ uptake. ${ }^{42} \mathrm{~A}$ new peak was also observed at $1716 \mathrm{~cm}^{-1}$, this corresponding to $\mathrm{C}=\mathrm{O}$ stretching vibrations of carboxylic group in RhB.

SEM micrograph of ARH before and after RhB adsorption is shown in Fig. 3a,b. ARH surface was observed to be smooth and with pores of various shapes and sizes; these pores may serve as medium for RhB absorption. The surface of ARH was, however, left rough after RhB uptake (Fig. 3b).

\subsection{Batch Adsorption Studies}

\subsubsection{Effects of $p H$ on RhB Uptake onto $A R H$}

The effects of initial solution $\mathrm{pH}$ on $\mathrm{RhB}$ uptake is depicted in Fig. 4. Optimum adsorption $(86.79 \%)$ was observed at $\mathrm{pH}$ of 3. $\mathrm{RhB}$ existence varies depending on the solution media, RhB may exist in its cationic form in solution $\mathrm{pH}$ range of 1 to 3 , lactonic form in solution $\mathrm{pH}$ of less than 1 and its zwitterionic form in
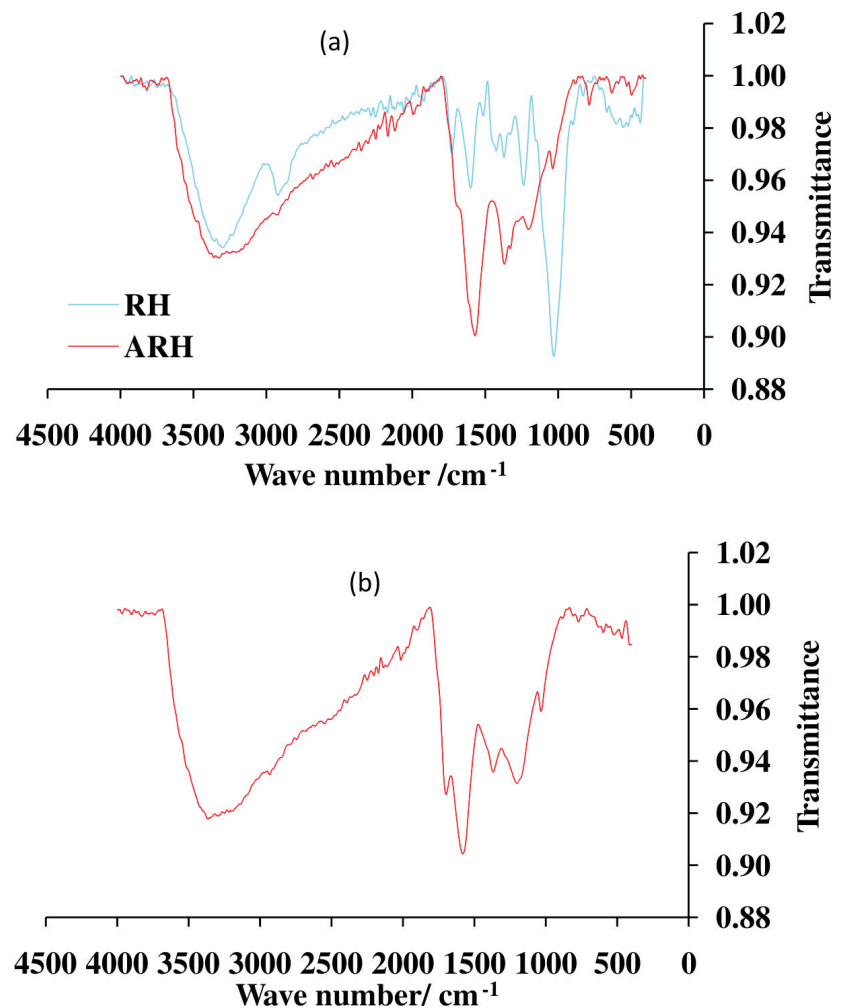

Figure 2 FTIR spectral (a) RH and ARH before RhB adsorption and (b) ARH after RhB adsorption 

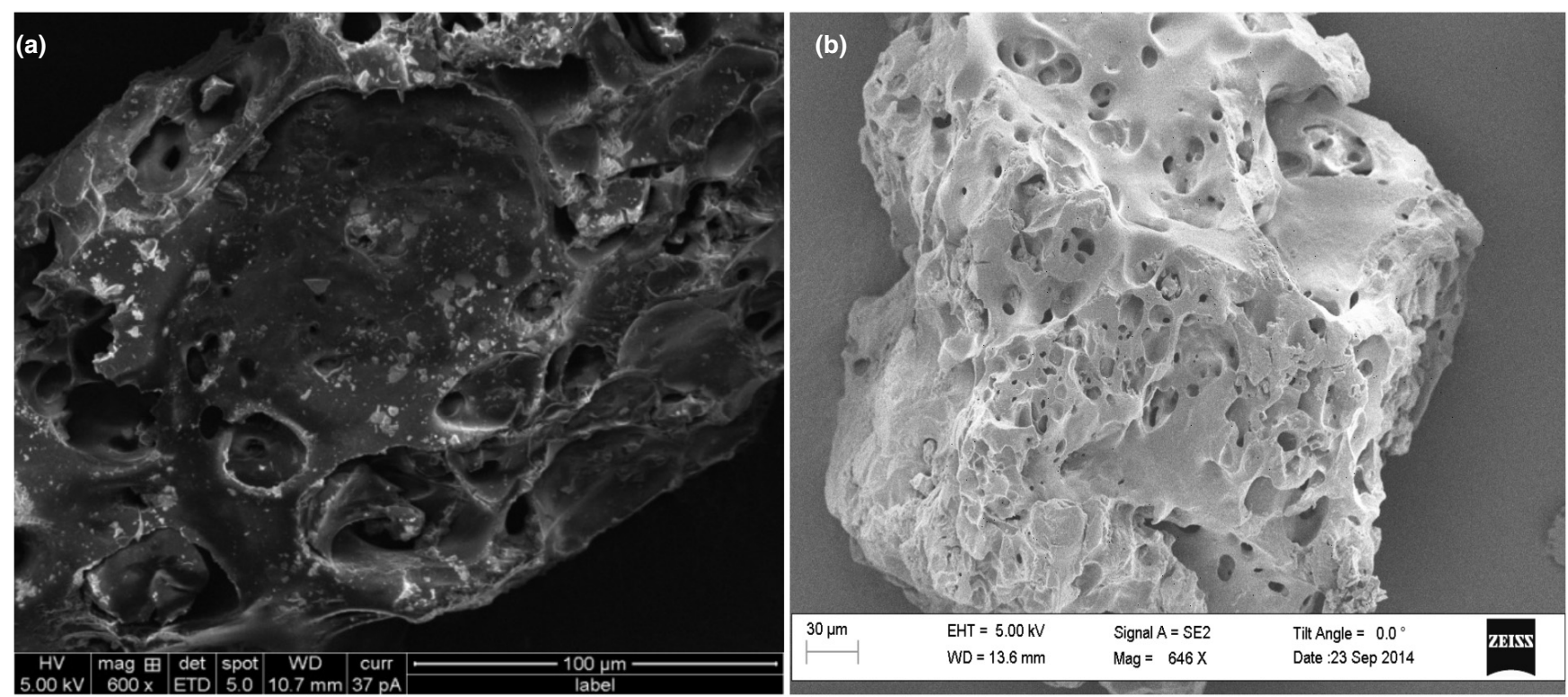

Figure 3 SEM of ARH before RhB adsorption (a) and after RhB adsorption (b)

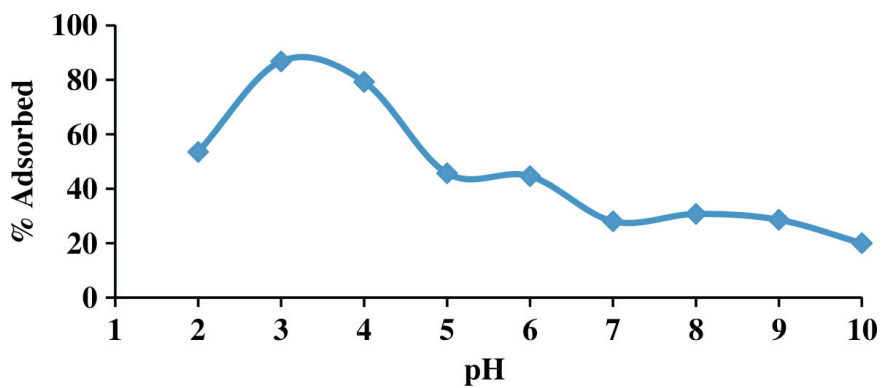

Figure 4 Effects of $\mathrm{pH}$ on $\mathrm{RhB}$ adsorption onto ARH. [Dosage $\left(1 \mathrm{~g} \mathrm{~L}^{-1}\right)$, agitation speed $(130 \mathrm{rpm})$, agitation time $(120 \mathrm{~min})$, temperature $\left(26^{\circ} \mathrm{C}\right)$, initial adsorbate concentration $\left.\left(100 \mathrm{mg} \mathrm{L}^{-1}\right)\right] .(n=3 ; 0.00 \leq \% E \leq 0.12)$.

solution with $\mathrm{pH}$ greater than 3.7. Adsorbent surface charge is also very important in $\mathrm{pH}$ study. The $\mathrm{pHpzc}$ of $\mathrm{ARH}$ obtained was 6.8 (Table 2). At pH below the pHpzc, the surface of the adsorbent is positively charged thus electrostatic repulsion between cationic $\mathrm{RhB}$ and adsorbent surface may result into low adsorption. As the $\mathrm{pH}$ of the solution increases, however, more sites are created for $\mathrm{RhB}$ adsorption thus RhB uptake increases. This phenomenon was obeyed between $\mathrm{pH}$ of 2 and 3. Zwitterionic form of $\mathrm{RhB}$, however, facilitates its dimer formation due to the attraction between the xanthenes and the carboxyl groups of the monomers. At above $\mathrm{pH}$ of 3.7 therefore large molecules of $\mathrm{RhB}$ are formed (dimer) thus adsorption becomes difficult. Maximum adsorption at $\mathrm{pH}$ of 3 have been previously reported by researchers. ${ }^{43,44,45}$

\subsubsection{Effects of Adsorbent Dosage on RhB Uptake onto ARH}

Rapid increase was observed in percentage adsorption when the adsorbent dosage was increased from $1 \mathrm{~g} \mathrm{~L}^{-1}$ to $2 \mathrm{~g} \mathrm{~L}^{-1}$ (Fig. 5). Increase in available adsorption site may have been responsible for this rapid increase. However, as the adsorbent dosage further increased, negligible increase was observed in percentage adsorption and percentage adsorption subsequently goes to equilibrium at dosage of $4 \mathrm{~g} \mathrm{~L}^{-1}$. Saturation of adsorption sites results into no further adsorption at high adsorbent dosage. ${ }^{46}$

\subsubsection{Effects of Concentration/Contact Time on RhB Uptake onto ARH}

For all the initial adsorbate concentrations considered, adsorp-

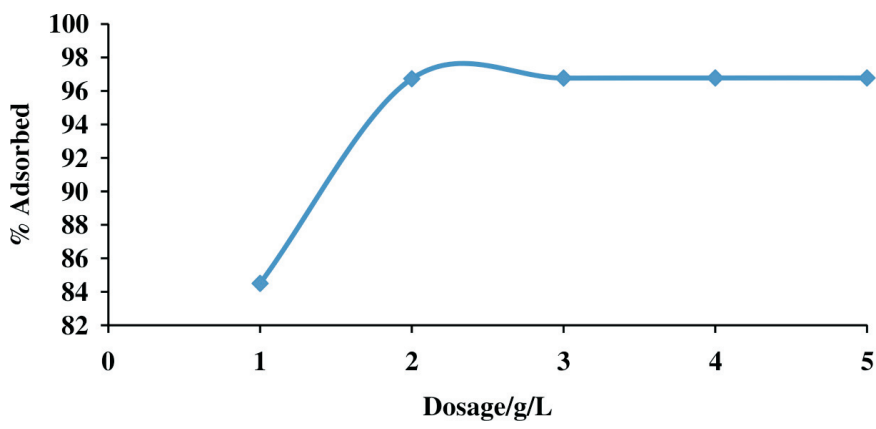

Figure 5 Effects of adsorbent dosage on RhB adsorption onto ARH. [Agitation speed $(130 \mathrm{rpm})$, initial concentration $\left(100 \mathrm{mg} \mathrm{L}^{-1}\right)$, temperature $\left.\left(26^{\circ} \mathrm{C}\right), \mathrm{pH}(3)\right] .(n=3 ; 0.00 \leq \% E \leq 0.14)$.

tion of RhB onto ARH was observed to be first rapid, followed by a gradual adsorption and subsequently equilibrium was attained within $120 \mathrm{~min}$. The initial rapid adsorption may have been to the surface of the adsorbent while the gradual adsorption results from continuous bombardment that aids percolation of RhB molecules into ARH pores. Various functional groups present on the surface of ARH may have been responsible for the surface adsorption. Surface modification was found to enhance adsorption capacity of ARH. Comparing ARH with RH in our recently reported work ${ }^{27}$ about $12 \%$ increase in quantity of $\mathrm{RhB}$ adsorbed was recorded. Quantity adsorbed at equilibrium ranged between $49.23 \mathrm{mg} \mathrm{g}^{-1}$ and $360.12 \mathrm{mg} \mathrm{g}^{-1}$. Quantity of RhB dye adsorbed at high concentration was observed to be higher when compared with our previously reported work. ${ }^{29}$ The low value of $\Delta q_{\mathrm{e}}$ for the Temkin isothermal studies suggests that adsorbate-adsorbate interactions may have occurred in the RhB-ARH system, this may account for high quantity adsorption recorded at high concentration. High initial concentration also provides enough driving force to overcome the mass transfer barrier between the aqueous and solid phase thus high adsorption at high concentrations.

\subsubsection{Effects of temperature on $R h B$ uptake onto $A R H$}

Quantity adsorbed decreased with increase in temperature, only about $23 \mathrm{mg} \mathrm{g}^{-1} \mathrm{RhB}$ was adsorbed at $60^{\circ} \mathrm{C}$ (Fig. 7). The dye molecule may have more affinity for $\mathrm{H}_{2} \mathrm{O}$ than adsorbent surface at high temperature. Break of established bonds between the 
RhB dye and adsorbent may also occur at high temperature thus resulting in decrease in quantity adsorbed at high temperature. ${ }^{47}$

\subsection{Adsorption Isothermal Studies}

Isotherm parameters for the adsorption of $\mathrm{RhB}$ onto $\mathrm{ARH}$ are listed on Table 3. The dimensionless separation factor $\left(R_{\mathrm{L}}\right)$ value obtained was 0.002 , suggesting that adsorption process was favourable. The Freundlich isotherm constant $n$ with a value greater than unity also corroborates favourable adsorption within the RhB-ARH system. The initial rapid adsorption that characterized the uptake of RhB onto ARH (Fig. 6) may have been onto a uniform site as a result of contact with activated surface functional groups. This is justified by the high $R^{2}$ value of the Langmuir isotherm model as well as low $\chi^{2}$ and $\Delta q_{\mathrm{e}}$ values (Table 3). Although monolayer adsorption dominates the uptake of $\mathrm{RhB}$ onto $\mathrm{ARH}$, however, the $R^{2}$ value for the Freundlich adsorption isotherm obtained was 0.9060 . Thus adsorption onto other surfaces such as percolation of $\mathrm{RhB}$ into the pores of $\mathrm{ARH}$ may also have occurred. The energy of adsorption as calculated from the D-R isotherm model is greater than $8 \mathrm{kJmol}^{-1}$ (Table 3) suggesting that the uptake of RhB onto ARH follows a chemical method. The maximum monolayer adsorption capacity $\left(q_{\max }\right)$ obtained to be $166.67 \mathrm{mg} \mathrm{g}^{-1}$ was compared with others previously reported in the literatures (Table 4) and ARH can be said to have exhibited better performance.

\subsection{Adsorption Kinetics Studies}

Adsorption kinetics have a great effect on adsorbent efficiency, it describes the rate of pollutant (adsorbate) uptake onto the adsorbent as well as controls the equilibrium time. Insight into adsorption mechanism was further established using the pseudo-first, pseudo-second, Elovich and Avrami kinetics models. Close agreement exists between the $q_{\text {cal }}$ and $q_{\text {exp }}$ for the pseudo-second-order kinetics model (Table 5), low SSE, $\Delta q_{\mathrm{e}}$ and $\chi^{2}$ as well as high $R^{2}$ values recorded for the pseudo-second-

Table 3 Parameters of Langmuir, Freundlich, Temkin and D-R adsorption isotherm for the uptake of RhB onto ARH.

\begin{tabular}{|c|c|c|}
\hline Isotherms & Constants & $\mathrm{ARH}$ \\
\hline Langmuir & $\begin{array}{l}q_{\max } / \mathrm{mg} \mathrm{g}^{-1} \\
K_{\mathrm{L}} / \mathrm{L}^{-1} \mathrm{mg}^{-1} \\
R_{\mathrm{L}} \\
R^{2} \\
\Delta q_{\mathrm{e}} \\
\chi^{2}\end{array}$ & $\begin{array}{l}166.67 \\
1.1999 \\
0.0021 \\
0.9860 \\
0.11 \\
3.22\end{array}$ \\
\hline Freundlich & $\begin{array}{l}K_{\mathrm{F}} \\
n \\
R^{2} \\
\Delta q_{\mathrm{e}} \\
\chi^{2}\end{array}$ & $\begin{array}{l}50.00 \\
3.70 \\
0.9060 \\
0.22 \\
77.49\end{array}$ \\
\hline Temkin & $\begin{array}{l}B \\
A / \mathrm{L}^{-1} \mathrm{~g}^{-1} \\
b / \mathrm{J} \mathrm{mol}^{-1} \\
R^{2} \\
\Delta q_{\mathrm{e}} \\
\chi^{2}\end{array}$ & $\begin{array}{l}24.01 \\
7.49 \\
103.88 \\
0.8150 \\
0.20 \\
54.71\end{array}$ \\
\hline D-R & $\begin{array}{l}q_{\mathrm{o}}\left(\mathrm{mg} \mathrm{g}^{-1}\right) \\
\beta / \mathrm{mol}^{2} \mathrm{KJ}^{-2} \\
E / \mathrm{kJ} \mathrm{mol}^{-1} \\
R^{2} \\
\Delta q_{\mathrm{e}} \\
\chi^{2}\end{array}$ & $\begin{array}{l}133.78 \\
0.0002 \\
50.00 \\
0.7274 \\
0.31 \\
13.07 \times 10^{3}\end{array}$ \\
\hline
\end{tabular}

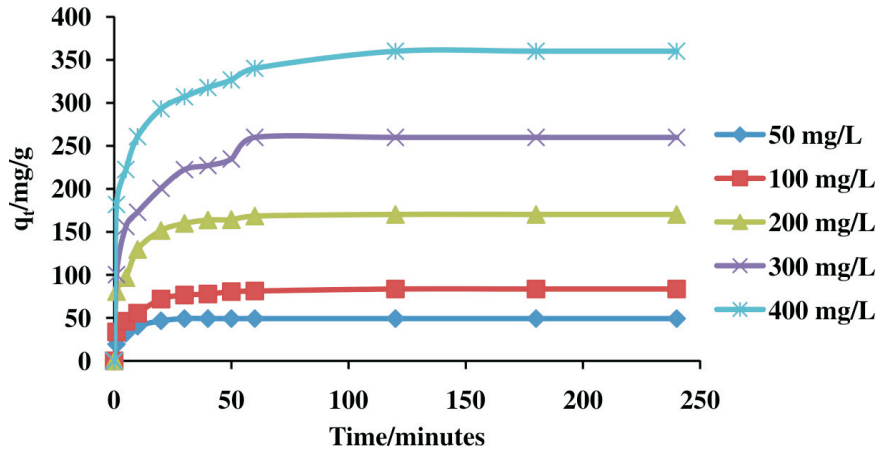

Figure 6 Effects of concentration/contact time on RhB adsorption onto ARH. [Dosage $(0.1 \mathrm{~g})$, temperature $\left(26^{\circ} \mathrm{C}\right)$ and agitation speed $(130 \mathrm{rpm})$, $\mathrm{pH}(3)](n=3 ; 0.01 \leq \% E \leq 0.02)$.

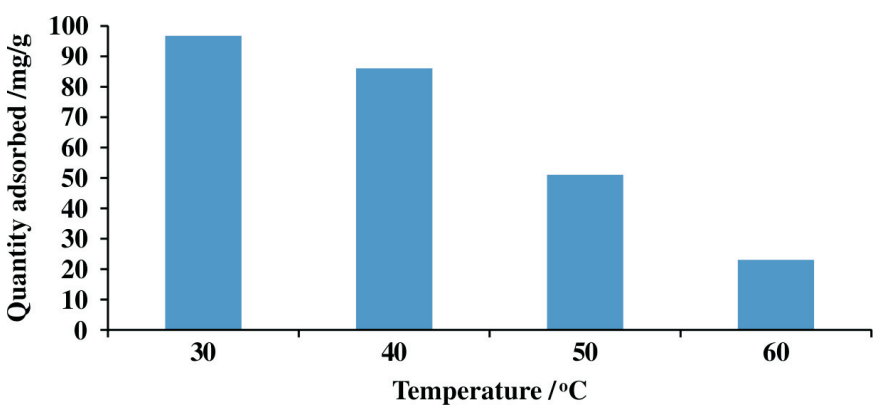

Figure 7 Effects of temperature on RhB adsorption onto ARH. [Agitation speed $(130 \mathrm{rpm})$, initial concentration $\left(100 \mathrm{mg} \mathrm{L}^{-1}\right)$, dosage $\left(1 \mathrm{~g} \mathrm{~L}^{-1}\right), \mathrm{pH}$ (3)] $(n=3 ; 0.00 \leq \% \mathrm{E} \leq 0.11)$.

order kinetics model suggests a good fitting of the kinetic data into this model. The adsorption data fitted well into the pseudo-second-order kinetic models thus indicating that uptake of RhB onto ARH may be chemical in nature. ${ }^{55}$ Pseudo-firstorder and Avrami kinetics models are not suitable for the RhB-ARH adsorption system. Elovich model is known to best describe a chemisorption adsorption mechanism system. ${ }^{56}$ Although low values were recorded for SSE, $\Delta q_{\mathrm{e}}$ and $\chi^{2}$ for the Elovich model, the pseudo-second kinetics better describes the kinetics of RhB-ARH system. A two stage adsorption profile was obtained for ARH-RhB system for initial concentration of $100 \mathrm{mg}$ $\mathrm{L}^{-1}$ to $400 \mathrm{mg} \mathrm{L}^{-1}$ while a single linear profile obtained for initial concentration of $50 \mathrm{mg} \mathrm{L}^{-1}$ suggest a single stage adsorption process (figure not shown). For the multilinear profile, the first steeper portion can be attributed to the boundary layer diffusion of $\mathrm{RhB}$ while the second linear portion corresponds to a gradual

Table 4 Comparison of the adsorption capacity of RhB onto ARH with some previous reports.

\begin{tabular}{lrc}
\hline Adsorbent & $q_{\max } / \mathrm{mg} \mathrm{g}^{-1}$ & Ref \\
\hline Kaolinite & 46.02 & 48 \\
Animal bone meal & 64.95 & 49 \\
Bangal seed gram husk & 133.34 & 50 \\
Bangal seed gram husk & 41.66 & 51 \\
Microwave treated nilotica leaf & 24.39 & 52 \\
Chemically treated nilotica leaf & 22.37 & 52 \\
Acid treated pine nut shell & 32.49 & 53 \\
Acid treated Macauba & 32.65 & 53 \\
Acid treated Carnauba & 35.28 & 53 \\
Dika nut char & 52.90 & 54 \\
Acid treated Raphia hookeri epicarp & 166.67 & This study \\
\hline
\end{tabular}


Table 5 Pseudo-first-order, pseudo-second-order, Elovich, Avrami and intraparticle diffusion kinetic model parameters for the adsorption of RhB onto ARH.

\begin{tabular}{|c|c|c|c|c|c|}
\hline \multirow[t]{2}{*}{ Constants } & \multicolumn{5}{|c|}{ ARH } \\
\hline & 50 & 100 & 200 & 300 & 400 \\
\hline$q_{\mathrm{exp}} / \mathrm{mg} \mathrm{g}^{-1}$ & 49.23 & 83.61 & 170.29 & 259.87 & 360.12 \\
\hline $\begin{array}{l}\text { Pseudo first order } \\
q_{\text {e calc }} / \mathrm{mg} \mathrm{g}^{-1} \\
K_{1} \times 10^{-2} / \mathrm{min}^{-1} \\
R^{2} \\
\text { SSE } \\
\chi^{2} \\
\Delta q_{\mathrm{e}}\end{array}$ & $\begin{array}{l}33.02 \\
12.92 \\
0.9994 \\
262.76 \\
7.96 \\
0.18\end{array}$ & $\begin{array}{l}44.36 \\
5.24 \\
0.9735 \\
1540.56 \\
34.73 \\
0.22\end{array}$ & $\begin{array}{l}82.45 \\
6.13 \\
0.9666 \\
7715.87 \\
93.58 \\
0.67\end{array}$ & $\begin{array}{l}95.45 \\
2.16 \\
0.9522 \\
27033.94 \\
283.22 \\
0.09\end{array}$ & $\begin{array}{l}155.66 \\
3.36 \\
0.9735 \\
41803.89 \\
268.56 \\
0.16\end{array}$ \\
\hline $\begin{array}{l}\text { Pseudo second order } \\
q_{\text {e calc }} / \mathrm{mg} \mathrm{g}^{-1} \\
K_{2} \times 10^{-3} / \mathrm{g} \mathrm{mg}^{-1} \mathrm{~min}^{-1} \\
R^{2} \\
\mathrm{SSE} \\
\chi^{2} \\
\Delta q_{\mathrm{e}}\end{array}$ & $\begin{array}{l}49.51 \\
16.90 \\
0.9999 \\
0.08 \\
0.00 \\
0.02\end{array}$ & $\begin{array}{l}84.75 \\
3.55 \\
0.9998 \\
1.29 \\
0.02 \\
0.04\end{array}$ & $\begin{array}{l}172.41 \\
2.39 \\
0.9999 \\
4.49 \\
0.03 \\
0.04\end{array}$ & $\begin{array}{l}263.16 \\
0.84 \\
0.9994 \\
10.82 \\
0.04 \\
0.04\end{array}$ & $\begin{array}{l}370.37 \\
0.62 \\
0.9996 \\
105.06 \\
0.28 \\
0.05\end{array}$ \\
\hline $\begin{array}{l}\text { Elovich } \\
\alpha_{\mathrm{EL}} / \mathrm{mg} \mathrm{g}^{-1} \mathrm{~min}^{-1} \\
\beta_{\mathrm{EL}} / \mathrm{g} \mathrm{mg}^{-1} \\
R^{2} \\
\mathrm{SSE} \\
\chi^{2} \\
\Delta q_{\mathrm{e}}\end{array}$ & $\begin{array}{l}607.80 \\
0.19 \\
0.8091 \\
35.16 \\
0.64 \\
0.11\end{array}$ & $\begin{array}{l}345.80 \\
0.09 \\
0.9092 \\
61.31 \\
0.67 \\
0.09\end{array}$ & $\begin{array}{l}1938.62 \\
0.06 \\
0.8792 \\
240.56 \\
1.29 \\
0.09\end{array}$ & $\begin{array}{l}962.21 \\
0.03 \\
0.9532 \\
365.57 \\
1.31 \\
0.09\end{array}$ & $\begin{array}{l}5470.37 \\
0.02 \\
0.9738 \\
293.78 \\
0.78 \\
0.05\end{array}$ \\
\hline $\begin{array}{l}\text { Avrami } \\
n_{\mathrm{AV}} \\
K_{\mathrm{AV}} / \mathrm{min}^{-1} \\
R^{2} \\
\mathrm{SSE} \\
\chi^{2} \\
\Delta q_{\mathrm{e}}\end{array}$ & $\begin{array}{l}0.58 \\
1.29 \\
0.9820 \\
2.19 \times 10^{3} \\
0.89 \times 10^{3} \\
0.31\end{array}$ & $\begin{array}{l}0.50 \\
1.69 \\
0.9631 \\
6.68 \times 10^{3} \\
3.53 \times 10^{3} \\
0.31\end{array}$ & $\begin{array}{l}0.49 \\
1.36 \\
0.9473 \\
28.31 \times 10^{3} \\
14.02 \times 10^{3} \\
0.31\end{array}$ & $\begin{array}{l}0.39 \\
1.87 \\
0.9919 \\
66.79 \times 10^{3} \\
46.38 \times 10^{3} \\
0.32\end{array}$ & $\begin{array}{l}0.34 \\
1.38 \\
0.9669 \\
12.87 \times 10^{4} \\
92.58 \times 10^{3} \\
0.32\end{array}$ \\
\hline $\begin{array}{l}\text { Intraparticle diffusion } \\
\mathrm{C}_{1} / \mathrm{mg} \mathrm{g}^{-1} \\
K_{1 \text { diff }} / \mathrm{mg} \mathrm{g}^{-1} \mathrm{~min}^{-1 / 2} \\
R_{1}^{2} \\
C_{2} \times 10^{2} / \mathrm{mg} \mathrm{g}^{-1} \\
K_{2 \text { diff }} / \mathrm{mg} \mathrm{g}^{-1} \mathrm{~min}^{-1 / 2} \\
R_{2}^{2}\end{array}$ & $\begin{array}{l}13.21 \\
7.89 \\
0.9690 \\
- \\
- \\
-\end{array}$ & $\begin{array}{l}22.07 \\
10.94 \\
0.9960 \\
0.75 \\
0.66 \\
0.7570\end{array}$ & $\begin{array}{l}56.27 \\
21.46 \\
0.9690 \\
1.58 \\
0.91 \\
0.7090\end{array}$ & $\begin{array}{l}81.18 \\
28.09 \\
0.9480 \\
2.12 \\
3.56 \\
0.620\end{array}$ & $\begin{array}{l}150.90 \\
32.63 \\
0.9900 \\
2.89 \\
5.23 \\
0.819\end{array}$ \\
\hline
\end{tabular}

sorption stage where intraparticle diffusion was the rate-limiting step and subsequently equilibrium was attained. Boundary layer diffusion may have dominated the uptake of RhB onto ARH in the $50 \mathrm{mg} \mathrm{L}^{-1}$ solution due to the ratio of available surface adsorption site and the RhB concentration in solution.

\subsection{Adsorption Thermodynamics}

Table 6 lists the calculated thermodynamic parameters and for the Van't Hoff plot. Negative enthalpy $\left(\Delta H^{\circ}\right)$ was obtained for the uptake of RhB onto ARH, this suggests that the adsorption process was exothermic in nature while the negative values of $\Delta S^{\circ}$ (Table 6) indicate decrease in the randomness at the solid-liquid interface during the adsorption of $\mathrm{RhB}$ onto ARH.

Table 6 Thermodynamic parameters for the uptake of RhB onto ARH.

\begin{tabular}{lcc|cccc}
\hline Adsorbent & $\begin{array}{c}\Delta \mathrm{H}^{\circ} \\
/ \mathrm{kJ} \mathrm{mol}^{-1}\end{array}$ & $\begin{array}{c}\Delta \mathrm{S}^{\circ} \\
/ \mathrm{J} \mathrm{mol}^{-1} \mathrm{~K}^{-1}\end{array}$ & \multicolumn{4}{|c}{\begin{tabular}{c}
\multicolumn{4}{c}{$\Delta \mathrm{G}^{\circ}$} \\
$/ \mathrm{kJ} \mathrm{mol}^{-1}$
\end{tabular}} \\
\hline \multirow{3}{*}{ ARH } & & & 303 & 313 & 323 & 333 \\
& -131.13 & -404.42 & -8.59 & -4.74 & -0.11 & 3.33 \\
\hline
\end{tabular}

$\Delta G^{\circ}$ values obtained for temperature range between 303 and $323^{\circ} \mathrm{K}$ were negative, negativity of $\Delta G^{\circ}$ decreased as the temperature increased and for the highest temperature considered $\left(333^{\circ} \mathrm{K}\right), \Delta G^{\circ}$ was found to be positive. This suggests that the spontaneity of the adsorption process decreased as temperature increased. The adsorption process was, however, more favourable at lower temperature. Chen et al. 2012, ${ }^{57}$ previously reported similar trend when they utilized Resin D301 in glyphosate adsorption.

\subsection{Desorption Studies of RhB-ARH System}

The desorption efficiencies by the three eluents used was found to be generally low with neutral $\mathrm{H}_{2} \mathrm{O}$ having the lowest desorption efficiency $(4.55 \%)$. Percentage desorption for $\mathrm{HCl}$ and acetic acid were recorded to be $31.82 \%$ and $36.36 \%$, respectively. Desorption efficiency followed the order $\mathrm{CH}_{3} \mathrm{COOH}>$ $\mathrm{HCl}>\mathrm{H}_{2} \mathrm{O}$. Chemisorption dominates the mechanism of RhB uptake onto ARH, this is well justified by the percentage desorption efficiency recorded using $\mathrm{CH}_{3} \mathrm{COOH}$. Possibility of low desorption is high for adsorbents with so many adsorption sites. Various surface functional groups in ARH facilitate several 
contacts points between the dye molecule and ARH thus large net adsorption energy and subsequently difficult dye desorption from adsorbent surface. ${ }^{58}$

\section{Conclusion}

$\mathrm{ARH}$, an adsorbent with multifunctional group surface was highly effective in the uptake of RhB from aqueous solution. Monolayer adsorption dominates the uptake of $\mathrm{RhB}$ onto ARH as the equilibrium adsorption data fitted best into the Langmuir adsorption isotherm. Some multilayer adsorption also occurred in the RhB-ARH system, with $R^{2}$ value of Freundlich adsorption isotherm being greater than 0.9 . The maximum monolayer adsorption capacity obtained was $166.67 \mathrm{mg} \mathrm{g}^{-1}$, and was found to be more effective than other adsorption systems previously reported in the literatures. The pseudo-second-order kinetics, energy of adsorption obtained from the D-R model as well as desorption efficiency suggests that uptake of RhB onto ARH was chemical in nature.

\section{Acknowledgement}

The authors gratefully acknowledge Miss Fola Oyinloye for linguistic editing of this work

\section{References}

1 K.A. Adegoke and O.S. Bello, Dye sequestration using agricultural wastes as adsorbents, Water Resour. Indust., 2015, 12, 8-24.

2 S. Banerjee, G.C. Sharma, R.K. Gautam, M.C. Chattopadhyaya, S.N Upadhyay and Y.C. Sharma, Removal of Malachite Green, a hazardous dye from aqueous solutions using Avena sativa (oat) hull as a potential adsorbent, J. Mol. Liq., 2016, 213, 162-172.

3 T.A. Khan, M. Nazir and E.A. Khan, Adsorptive removal of rhodamine B from textile wastewater using water chestnut (Trapa natans L.) peel: adsorption dynamics and kinetic studies, Toxicol. Environ.Chem., 2013, 95(6), 919-931.

4 K.Y. Foo and B.H. Hameed, A short review of activated carbon assisted electrosorptionprocess: an overview, current stage and future prospects, J. Hazard. Mater., 2009, 170, 552-559.

5 Suhas, V.K. Gupta, P.J.M. Carrott, R. Singh, M. Chaudhary and S. Kushwaha, Cellulose: a review as natural, modified and activated carbon adsorbent, Bioresour. Technol., 2016, 216, 1066-1076.

6 F.K. Yuen and B.H. Hameed, Recent developments in the preparation and regeneration of activated carbons by microwaves, Adv. Colloid Interface Sci., 2009, DOI: 10.1016/j.cis.2008.12.005

7 I.A.W. Tan, A.L. Ahmad and B.H. Hameed, Preparation of activated carbon from coconut husk: optimization study on removal of 2,4,6-trichlorophenol using response surface methodology, J. Hazard. Mater., 2008, 153, 709-717.

8 T. Santhi, S. Manonmani and T. Smith, Kinetics and isotherm studies on cationic dyes adsorption onto Annona squmosa seed activated carbon, Int. J. Eng. Sci. Technol., 2010, 2(3), 287-295.

9 M. Bansal, D. Singh and V.K. Garg, A comparative study for the removal of hexavalent chromium from aqueous solution by agriculture wastes' carbons, J. Hazard. Mater., 2009, 171, 83-92.

10 J. Acharya, J.N. Sahu, B.K. Sahoo, C.R. Mohanty and B.C. Meikap, Removal of chromium(VI) from wastewater by activated carbon developed from Tamarind wood activated with zinc chloride, Chem. Eng. J., 2009, 150, 25-39.

11 D. Duranoğlu, A.W. Trochimczuk and U. Beker, A comparison study of peach stone andacrylonitrile-divinylbenzene copolymer based activated carbons as chromium(VI) sorbents, Chem. Eng. J., 2010, 165, 56-63.

12 O.S. Bello and M.A. Ahmad, Adsorptive removal of a synthetic textile dye using cocoa pod husks, Toxicol. Environ. Chem., 2011, 93(7), 1298-1308.

13 X.J. Wang,Y. Wang, X.Wang, M.Liu, X.Q.Xia, D.Q. Yin,Y.L. Zhang and J.F. Zhao, Microwave-assisted preparation of bamboo charcoal-based iron-containing adsorbents for Cr(VI) removal, Chem. Eng. J., 2011, 174, 326-332

14 O.S. Bello and M.A. Ahmad, Removal of Remazol Brilliant Violet-5R dye using periwinkle shells, Chem. Ecol., 2011, 27(5), 481-492.
15 K.J. Cronje, K. Chetty, M. Carsky, J.N. Sahuand and B.C. Meikap, Optimization of chromium(VI) sorption potential using developed activated carbon from sugarcane bagasse with chemical activation by zinc chloride, Desalination, 2011, 275, 276-284.

16 E. Ŏzdemir, D. Duranoğlu, U. Beker and A.Ŏ. Avc, Process optimization for $\mathrm{Cr}(\mathrm{VI})$ adsorption onto activated carbons by experimental design, Chem. Eng. J., 2011, 172, 207-218.

17 Z.A. AL-Othman, R. Ali and M. Naushad, Hexavalent chromium removal from aqueous medium by activated carbon prepared from peanut shell: adsorption kinetics, equilibrium and thermodynamic studies, Chem. Eng. J., 2012, 184, 238-247.

18 M.G. Fonseca, M.M. Oliveira and L.N.H. Arakaki, Removal of cadmium, zinc, manganese and chromium cations from aqueous solution by a clay mineral, J. Hazard. Mater. B, 2006, 137, 288-292.

19 R.H. Hessa, A. Arami-Niya, W.M.A.W. Daud and J.N. Sahu, Preparation and characterization of activated carbon from apple waste by microwave-assisted phosphoric acid activation: application in methylene blue adsorption, BioResources, 2013, 8(2), 2950-2966.

20 E.O. Augustine, Intraparticle diffusion process for lead (II) biosorption onto mansonia wood sawdust, Bioresour. Technol., 2010, 101, 5868-5876.

21 M.C. Somasekhara Reddy, et al., Bengal gram seed husk as an adsorbent for the removal of dye from aqueous solutions - Batch studies. Arabian J. Chem. (2014), http://dx.doi.org/10.1016/j.arabjc.2013.09.029

22 R. Elmoubarki, F.Z. Mahjoubi, H. Tounsadi, J. Moustadraf, M. Abdennouri, A. Zouhri, A. El Albani and N. Barka, Adsorption of textile dyes on raw and decanted Moroccan clays: kinetics, equilibrium and thermodynamics, Water Resour. Indust., 2015, 9, 16-29.

23 H. Kołoczek, J. Chwastowski and W. Żukowski, Peat and coconut fiber as biofilters for chromium adsorption from contaminated wastewaters, Environ. Sci. Pollut. Res., 2015, DOI 10.1007/s11356-015-5285-x.

24 A. Joanna, Ł. Krzysztof, T. Krzysztof and J.P. Bartosz, Potential for chromium (VI) bioremediation by the aquatic carnivorous plant Utricularia gibba L. (Lentibulariaceae), Environ. Sci. Pollut. Res., 2015, 22, 9742-9748.

25 T.A. Khan, R. Rahman, I. Ali, E.A. Khan and A.A. Mukhlif, Removal of malachite green from aqueous solution using waste pea shells as low-cost adsorbent - adsorption isotherms and dynamics, Toxicol. Environ. Chem., 2014, DOI: 10.1080/02772248.2014.969268

26 T.A. Khan, S. Sharma, E.A. Khan and A.A. Mukhlif, Removal of congo red and basic violet 1 by chir pine (Pinus roxburghii) sawdust, a saw mill waste: batch and column studies, Toxicol. Environ. Chem., 2014, 96(4), 555-568.

27 A.A. Inyinbor, F.A. Adekola and G.A. Olatunji, Kinetic and thermodynamic modeling of liquid phase adsorption of Rhodamine B dye onto Raphia hookerie fruit epicarp, Water Resour. Indust., 2016, 15, 14-27.

28 H. Gong, Z. Chen, Y. Fan, M. Zhang, W. Wu and W. Wang, Surface modification of activated carbon for siloxane adsorption, Renew. Energy, 2015, 83, 144-150.

29 A.A. Inyinbor, F.A. Adekola and G.A. Olatunji, Adsorption of rhodamine B dye from aqueous solution on Irvingia gabonensis biomass: kinetics and thermodynamics studies, S. Afr. J. Chem., 2015, 68 , 115-125.

30 I. Langmuir, The constitutional and fundamental properties of solids and liquids. J. Am. Chem. Soc., 1916, 38, 2221-2295.

31 H.M.F. Freundlich, Over the adsorption in solution, Z. Phys. Chem., 1906, 57, 385-470.

32 M.I. Temkin and V. Pyzhev, Kinetics of ammonia synthesis on promoted iron catalyst, Acta Physiochim.USSR, 1940, 12, 327-356.

33 M.M. Dubinin and L.V. Radushkevich, Equation of the characteristic curve of activated charcoal, Proc. Acad. Sci. Phys. Chem. USSR, 1947, $55,331-333$.

34 S. Lagergren and B.K. Svenska, On the theory of so-called adsorption of materials, R. Swed. Acad. Sci. Doc, Band, 1898, 24, 1-13.

35 Y.S. Ho and G. McKay, Pseudo-second order model for sorption processes, Proc. Biochem., 1999, 34, 451-465.

36 C. Aharoni and M. Ungarish, Kinetics of activated chemisorptions. Part I: the non-Elovichian part of the isotherm, J. Chem. Soc. Farad. Trans., 1976, 72, 265-268.

37 M. Avrami, Kinetics of phase change: transformation-time relations for random distribution of nuclei. J. Chem. Phys., 1940, 8, 212-224. 
38 W.J. Weber and J.C. Morris, Kinetics of adsorption on carbon from solution, J. Sanity Eng. Div. Am. Soc. Civil Eng., 1963, 89, 31-59.

39 A.A. Inyinbor, F.A., Adekola and G.A. Olatunji, EDTA modified Irvingia gabonensis: an efficient bioresource material for the removal of Rhodamine B. Pakistan J. Anal. Environ. Chem., 2015, 16(2), 38-45.

40 X. Xu, B. Gao, X. Tan, Q. Yue, Q. Zhong and Q. Li, Characteristics of amine-crosslinked wheat straw and its adsorption mechanisms for phosphate and chromium (VI) removal from aqueous solution, Carbohydr. Polym., 2011, 84, 1054-1060.

41 R. Kumar, M.A. Barakat, Y.A. Daza, H.L. Woodcock and J.N. Kuhn, EDTA functionalized silica for the removal of $\mathrm{Cu}(\mathrm{II}), \mathrm{Zn}$ (II) and NI(II) from aqueous solution, J. Colloid Interface Sci., 2013, 408, 200-205.

42 O.S. Bello and M.A. Ahmad, Coconut (Cocos nucifera). Shell based activated carbon for the removal of Malachite Green Dye from aqueous solutions, Sep. Sci. Technol., 2012, 47(6), 903-912.

43 A.A. Inyinbor, F.A., Adekola and G.A. Olatunji, Adsorption of Rhodamine B from aqueous effluent using treated epicarp of Raphia hookerie, Covenant Univ. J. Phys. Life Sci., 2014, 2(2), 83-101.

44 Y. Huang, X. Zheng S. Feng, Z. Guo and S. Liang, Enhancement of rhodamine $\mathrm{B}$ removal by modifying activated carbon developed from Lythrum salicaria L. with pyruvic acid, Colloids Surfaces A: Physicochem. Eng. Aspects, 2016, 489, 154-162.

45 L. Ma, Y. Xi, H. He, G.A. Ayoko, R. Zhu, J. Zhu, Efficiency of Fe-montmorillonite on the removal of Rhodamine B and hexavalent chromium from aqueous solution, Appl. Clay Sci., 2016, 120, 9-15.

46 A.E. Pirbazari, E. Saberikhah and S.S. Habibzadeh Kozani, $\mathrm{Fe}_{3} \mathrm{O}_{4}-$ wheat straw: preparation, characterization and its application for methylene blue adsorption, Water Resour. Indust., 2014, 7-8, $23-37$.

47 A.M. Aljeboree, A.N. Abass and A.F. Ayad, Kinetics and equilibrium study for the adsorption of textile dyes on coconut shell activated carbon. Arabian J. Chem., 2014, http://dx.doi.org/10.1016/j.arabjc.2014.01.020.

48 T.A. Khan, S. Dahiya and I. Ali, Use of kaolinite as adsorbent: equilibrium, dynamics and thermodynamic studies on the adsorption of Rhodamine B from aqueous solution, Appl. Clay Sci., 2012, 69, 58-66.

49 M. El Haddad, R. Mamouni, N. Saffaj and S. Lazar, Evaluation of performance of animal bone meal as a new low cost adsorbent for the removal of a cationic dye Rhodamine B from aqueous solutions, J. Saudi Chem. Soc., 2012, http://dx.doi.org/10.1016/j.jscs.2012.08.005

50 M.C. Somasekhara Reddy and V. Nirmala, Bengal gram seed husk as an adsorbent for the removal of dyes from aqueous solutions - Equilibrium studies, Arabian J. Chem., 2013, http://dx.doi.org/10.1016/j.arabjc.2013.09.002

51 M.C. Somasekhara Reddy, V. Nirmala and C. Ashwini, Bengal Gram Seed Husk as an adsorbent for the removal of dye from aqueous solutions - Batch studies, Arabian J. Chem., 2014, http://dx.doi.org/10.1016/j.arabjc.2013.09.029

52 T. Santhi, A.L. Prasad and S. Manonmani, A comparative study of microwave and chemically treated Acacia nilotica leaf as an eco friendly adsorbent for the removal of rhodamine B dye from aqueous solution, Arabian J. Chem., 2014, 7, 494-503.

53 V.S. Lacerda, J.B. Lŏpez-Sotelo, A. Correa-Guimarăes, S. Hernăndez-Navarro, M. Sănchez-Băscones, L.M. Navas-Gracia, P. MartínRamos and J. Martín-Gil, Rhodamine B removal with activated carbons obtained from lignocellulosic waste, J. Environ. Manage., 2015, $155,67-76$.

54 A.A. Inyinbor, F.A., Adekola and G.A. Olatunji, Liquid phase adsorptions of Rhodamine B dye onto raw and chitosan supported mesoporous adsorbents: isotherms and kinetics studies, Appl. Water Sci., (2016), 1-11, DOI: 10.1007/s13201-016-0405-4, http://link.springer.com/article/10.1007/s13201-016-0405-4

55 Y. Liu, C. Dong, C. Wei, W. Yuan and K. Li, Adsorption of levofloxacin onto an iron-pillared montmorillonite (clay mineral): kinetics, equilibrium and mechanism, Appl. Clay Sci., 2015, 118, 301-307.

56 H.I. Inyang, A. Onwawoma and S. Bae, The Elovich equation as a predictor of lead and cadmium sorption rates on contaminant barrier minerals, Soil Tillage Res., 2016, 155, 124-132.

57 F. Chen, C.Zhou, G. Li and F. Peng, Thermodynamics and kinetics of glyphosate adsorption on resin D301. Arabian J. Chem., 2012, http://dx.doi.org/10.1016/j.arabjc.2012.04.014

58 M.E. Fernandez, G.V. Nunell, P.R. Bonelli and A.L. Cukierman, Effectiveness of Cupressus sempervirens cones as biosorbent for the removal of basic dyes from aqueous solutions in batch and dynamic modes, Bioresour. Technol. 2010, 101, 9500-9507. 